\title{
SOCIAL COMPETENCE IN 18-YEARS-OLD STUDENTS WHO HAD PERFORMED AN AGGRESSIVE ACT AT SCHOOL
}

\author{
Ivanka Boncheva ${ }^{1}$, Stefanka Tomcheva ${ }^{2}$. \\ 1) Department of Psychiatry and Medical Psychology, Medical University - Varna, \\ Bulgaria, \\ 2) Psychologist, Vocational school of mechanics, electronics, telecommunication \\ and transport "Hristo Botev" - Shumen, Bulgaria.
}

\begin{abstract}
:
The social competence as a general concept, consist of social, emotional, cognitive and behavioral skills. It is regarded as a basic quality of effectiveness at social interactions associated with successful behavioral patterns.

Social competence is related with variation in the ability to react in different situation, learn from past experiences, and apply the past experience to the changes in social interactions.

The present writing is aimed to define the relation between the level of forming a social competence and aggressive behavior at school of 18 -years-old students.

The relation social competence and aggressive behavior is analysed by the Giessen Test (GT). The methodology is suitable for studying crucial social qualities and reacts.

The subjects of the research were two groups of students - a group of students with aggressive behavior and a referential group.

The results show a tendency of increased selfesteem, own social popularity and attractiveness all of them combined with insufficient self-understanding and insufficient self-control in the students with aggressive behavior

The data lead to conclusion that the analysed students who had performed aggressive acts at school do not have considerable deviations of the average values according to the scales of the GT. Their behavior is a result of not well formed aggressive impulse and lacks of mature self-assessment.
\end{abstract}

Key words: social competence, aggressive behavior, Giessen Test, social interaction

One of the main tasks of the juvenile age is the successful entering in the system of social relations based on adopted standards and rules, which regulate these relations. An important requirement of the society to the young man is the ability for regulating and controlling his own behavior. The adolescents are expected to be socially competent.

Levterova D. (1) defines the competence as a system set up from cognitive notions and abilities, which are simply revealed in different behavioral models and varied areas of activity, which lead to positive result.

Among the basic forms of competence stands out the social competence like general capacity for effective social functioning, which is connected with resultant behavioral models and which includes self - knowledge, reflexion, initiative, personal responsibility for words and actions.

There are many definitions for social competence. Semrud-Clikeman (2) defines the social competence as a multidimensional concept made up from social, emotional, cognitive and behavioral abilities, which are necessary for successful social adaptation. This concept also includes the capability for variability of the reaction in different situations, the learning from past experience and the use of this experience when the social interactions change.

According to Harlow H. (3) the social competency is a necessary premise for successful integration between the person and the society.

Reschly and Gresham (4) connect the social competence with the adaptive behavior and the social abilities - self - regulation of the behavior and problem solving.

Meliburda EL. (5), Petrovskaya LA. (6), Gresham F M. (7) connect the social competence with the adaptive behavior and put it this way in new dimension. The social competence begins to be defined as a specific level of adaptation to the successful performance of the social roles.

In the examined theoretical formulations what makes impression is that the most authors have drawn the content of the definition "social competence" in their works mainly 
with children. The dimensions, the particularities and the detailing of the social competence as a set of abilities and capabilities urged us to seek the connection between the degree of forming the social competence and the aggressive acts of behavior in students of full age.

\section{AIM, MATERIALAND METHODS}

The present working out aims at the study of the connection between the degree of forming the social competence and the aggressive behavior in 18 -years old students.
We have examined an excerpt from 40 students from "Hristo Botev" High school for mechanical techniques, electronics, telecommunications and transport in Shumen. The students are of full age. The examined students are divided in two groups - 20 students, which have performed aggressive acts during the period of IX - XII grade, and 20 students for a reference group.

For analyzing the connections "social competence - aggressive behavior" is used the Giessen test $(8,9)$.

\section{RESULTS}

Table 1. Giessen -test Results

\begin{tabular}{|c|c|c|c|c|c|c|}
\hline Scales & $\begin{array}{c}\text { Group with aggressive } \\
\text { behavior }\end{array}$ & Reference group & \multicolumn{2}{|c|}{$\begin{array}{c}\text { Norms according to } \\
\text { Iv. Karagyozov }\end{array}$} & Lower limit & Higher limit \\
\cline { 4 - 5 } & & & $\mathrm{X}$ & $\mathrm{s}$ & & \\
\hline I & 37.9 & 40.3 & 26.8 & 6.1 & 20.7 & 32.9 \\
\hline II & 23.45 & 24.25 & 25.9 & 4.4 & 21.5 & 30.3 \\
\hline III & 25.75 & 28.95 & 27.1 & 4.9 & 22.2 & 32.0 \\
\hline IV & 26.45 & 25.4 & 24.7 & 6.4 & 18.3 & 31.1 \\
\hline V & 26.35 & 25.3 & 21.2 & 6.8 & 14.4 & 28.0 \\
\hline VI & 17.3 & 18.1 & 16.6 & 4.4 & 12.2 & 21.0 \\
\hline C & 8.3 & 5.45 & 7.1 & 5.5 & 1.6 & 12.6 \\
\hline E & 13.15 & 15.3 & 11.4 & 8.3 & 3.1 & 19.7 \\
\hline
\end{tabular}

Regarding to the first scale - Social resonance the average values in both groups are to significant degree increased. In higher limit with norm 32.9, the average values of the examined groups are respectively 37.9 in the group with aggressive acts and $\mathbf{4 0 . 3}$ in the reference group. The results give us reason to think that in their ideas for self social reputation, attractiveness and popularity, the adolescents have given themselves a higher value.

In the Dominance / Subordination, the values in both groups are within the norm, the average values are to the lower limit $\mathbf{2 1 . 5}$, in which is polarily presented the dominant role type of interrelations. In the group with aggressive acts - 23.45, in the reference group - 24.25. The personality features, which complete one another and which identify themselves with the defensive forms of behavior, are reflected in the desire to prove oneself through ambition for superiority, claims for leadership, perversion, aggressiveness and impulsiveness.

Regarding to the third scale - . Intrapsychic control expressed in the polar types - overcontrol / reduced control, the values in both groups are within the norm. What makes impression is that in the group with aggressive acts the values are 25.75 , which orients them to the lower limit of the norm $-\mathbf{2 2 . 2}$ / reduced self - control /. In the referent group the average values are 28.95 , a result oriented to the higher limit of the norm 32.0 / increased self - control /.

In the forth scale - Primary mood with the represented depressive / hypomanic types. In lower limit of the norm 18.3 and higher limit of the norm - 31.1, the average values of both groups are in the perfect middle, respectively for the group with aggressive acts $\mathbf{- 2 6 . 4 5}$ and for the reference group - 25.4. The questions in this scale seek the predominant mood, which underlies the formation of aggressive reaction - directed outwards or to the self I.

Regarding the fifth scale - Abilities of contact and communication - open/ closed type. The average values of the examined groups are around the higher limit of the norm - 28.0. In the group with aggressive acts the average values are 26.35, in the referent group -25.3 . The average values of the abilities for social contacts and social behaviour give us a reason to think that the examined students determine and experience themselves as a closed type - mistrustful, suspicious, hiding their need for love.

In the sixth scale - Social abilities - social potency / social impotence, the average values in both groups are in the higher limit of the norm / $21.0 /$, where is located the social impotent type. The aggressive group -17.3 and the reference group - 18.1. The examined groups, regarding the contents of the gained social experience, accept 
themselves rather as insecure in the social interactions, incapable for healthy and enduring interpersonal relations. One can feel a certain degree of lack of self - trust.

The scale "Average valuations" is within the norm in both groups. The higher average value in the group with aggressive acts / $\mathbf{8 . 3}$ /,on the background of the previous scales, we are inclined to interpret as and insufficient self - understanding.

The usage of "Extreme valuations" is with high frequency in both groups. In the group with aggressive acts $-13,15$, which speaks for low self - control and correlates positive with the results in the third scale. We think that the higher values in the reference group - 15.3, are due to well formed abilities for expressive behaviour. The reference group has the capabilities to give verbal expressions of the subjective experiences and manages to control the intensity of the emotions.

\section{DISCUSSION:}

The results allow us to see the connection between the degree of formation the social competence and the aggressive behavior.

According to Krokinskaya OK. (2005) without the necessary level of social competence or its insufficient formation, conditions for verbal and physical aggression, problematic behavior, interpersonal and internal personal conflicts are at hand.

The results on the first scale - the social approval confirms the understanding that both groups of examined students to the higher degree feel and understand themselves as popular and attractive with an overdose of self-confidence in their social prestige. This, compared with the results in the fifth scale/ the abilities for contact and communication / and sixth scale / social abilities/, make us think that with the examined students is observed rather fear of rejection and ambition for social acceptance and approval, than the feeling, that it is so.

In the defining of themselves as closed type / scale V / and socially impotent type / scale VI / there is an intense sensitivity to interpersonal and internal personal problem, with which the students come across. The abilities for contact are motivated from the adjustment "trust - mistrust", which give us a reason to think that there are indicators for trust crisis.

The values in the scale for dominance define the ambition of the adolescent to seek and to aim to control over the setting and the conditions. The reference group shows different behavior from the aggressive one and a premise for this is the higher level of their ability to choose social reference points and to organize their actions according to those reference points. The social capabilities in this students are like "web of direct aims and situative relative behaviors."

While in the group with aggressive acts the ambition to stand their grounds, to control the setting and actions with superiority and perversion corresponds with the strong significance of the personal reading if the situations and with certain deficits in the formation of the abilities for sensitivity and understanding of the social interactions.

Indicator for the differences in the formation of reactions to situations in both examined groups can be found in the third scale / inter psychic control/. In the reference group the average values put them in the pole of increased self - control. The degree of formation of abilities for mastering spontaneity and impulsiveness is higher. The social abilities in this group are expressed through behavioral indicators for co - operation and problems prevention.

In the group with aggressive acts the self - control is reduced. The aggressive answer, with which they react, is due rather to incapability to measure off their own emotional condition. In social - psychological aspect the emotion caused by "success - failure" are included in the process of behavior regulation based on gained experience. This make us think that in the students with aggressive behavior this is not a consequence from the lack of social abilities, but from the fact that they do not manage to apply this abilities adequate and effective in unexpected situations.

\section{CONCLUSIONS:}

1. The examined students, which have done aggressive act in school show deviation from the norm on the scale of Giessen's test. Their behavior is rather result from unsuitably educated aggressive impulse and lack of mature self - evaluation.

2. In the degree of formation of social competence high deviations from the norm are not observed. The emotional - volitional regulation of the behavior affects on the result of the used social abilities in terms of the effective functioning in the problematic social situation, which is necessary to be solved from the students with aggressive behavior.

3. The aggressive behavior of the students is not a result from the ignorance and the non - compliance with the social standards, but it is rather a consequence of a fast cognitive revision of some external stimulus. 


\section{REFERENCES:}

1. Levterova D.: Social Competence I Vol. „Paisii Hilendarski“- Institute. Plovdiv, 2009 [In Bulgarian]

2. Semrud-Clikeman M.: Social competence in children. New York, Springer Science - Bussines Media, 2007

3. Harlow HF, Harlow MK.: Learning to love. Am. Scientist, 1966, pp. 240280

4. Reschly DJ, Gresham FM.: Current neuropsychological diagnosis of learning problems: A leap of falth. In: Reynolds C. R. Child neuropsychology: techniques of diagnosis and treatment, New York, Plenum, 1989, pp. 503-519

5. Melibruda EL. You - We: Psychological capacities for better communication. M., Progress. 1986 [in Russian] 6. Petrovskaya LA. Communication competence. M., Publisher UM, 1989 [in Russian]

7. Gresham FM. Social Skills Instruction for Exceptional Children Theory into Practice. In: Exceptional Children in the School. 1982, 21(2):pp. 120-135
8. Kokoshkarova A. Psychological study of personality in clinical practice. Sf. "Medicine and Sport", 1984 [in Bulgarian]

9. Karagyozov Iv. Diagnostics of psychological developments' deviations. UP ,St.St. Cyril and Methodius “, V. Tarnovo, 1993 [In Bulgarian]

10. Krokinskaya OK, Possel YA. Social subconscious: sociological and psychosociological aspects. Piter. 2005 [in Russian]

\section{Address for correspondence:}

Assos. Prof. Ivanka Boncheva, PhD.

Department of Psychiatry and Medical Psychology,

Medical University - Varna, Bulgaria,

1, Hr. Smirnenski Boul., 9010 Varna, Bulgaria,

Mobile: +359887 722581

E-mail: ibontcheva@yahoo.com; 